\title{
AHNAK2 is a potential prognostic biomarker in patients with PDAC
}

\author{
Di Lu ${ }^{1}$, Junxiong Wang ${ }^{1}$, Xiaoyan Shi ${ }^{2}$, Bing Yue ${ }^{2}$ and Jianyu Hao ${ }^{1}$ \\ ${ }^{1}$ Department of Gastroenterology, Beijing Chao-Yang Hospital, Capital Medical University, Beijing 100020, China \\ ${ }^{2}$ Department of Pathology, Beijing Friendship Hospital, Capital Medical University, Beijing 100050, China \\ Correspondence to: Jianyu Hao, email: haojianyu@medmail.com.cn
}

Keywords: AHNAK2, pancreatic ductal adenocarcinoma, overall survival, prognostic factor, nomogram

Received: October 09, $2016 \quad$ Accepted: February 21, $2017 \quad$ Published: March 07, 2017

Copyright: Lu et al. This is an open-access article distributed under the terms of the Creative Commons Attribution License (CC-BY), which permits unrestricted use, distribution, and reproduction in any medium, provided the original author and source are credited.

\section{ABSTRACT}

Background: AHNAK nucleoprotein 2 (AHNAK2) belongs to the AHNAK protein family. The studies of AHNAK2 are limited. A recent study reported that AHNAK2 might be a biomarker for pancreatic ductal adenocarcinoma (PDAC); however, tissue-based experiments have not been conducted. The aim of this study was to determine the tissue expression of AHNAK2 and to find the correlation between AHNAK2 and overall survival rate in PDAC.

Results: AHNAK2 is highly expressed in PDAC $(n=79)$ compared with adjacent normal tissues $(n=64, P<0.001)$. Overexpression of AHNAK2 showed a significant relationship with a lower overall survival rate $(P=0.033)$ in PDAC patients. The predictive value of increased expression of AHNAK2 remains relevant in patients with AJCC grade above II $(n=43, P=0.006)$ or lymph node metastasis $(n=32, P=0.004)$. Cox regression analysis showed that AHNAK2 expression $(P=0.003)$ and pathology grade $(P<0.001)$ are independent prognostic factors for PDAC. The nomogram model was performed to predict the 1- and 3-year survival rates based on Cox regression. The $\mathrm{C}$-index was $\mathbf{0 . 6 1}$. The calibration curves were also made to show the association between the observed and predicted probability of the overall survival rates.

Materials and Methods: AHNAK2 expression was performed in tissue microarrays by immunohistochemistry. The overall survival rate analysis was performed using the Kaplan-Meier method, Cox proportional hazards regression, and a nomogram model.

Conclusions: AHNAK2 is overexpressed in PDAC tissues and is an independent prognostic factor in patients with PDAC.

\section{INTRODUCTION}

Pancreatic ductal adenocarcinoma (PDAC), the major pathologic type of pancreatic cancer, is one of the most frequent malignant tumors worldwide [1]. In the United States, the 5-year relative survival rate of PDAC is $<10 \%$ due to the low detection rate in the early stage [2]. Moreover, PDAC is sometimes difficult to distinguish from other pancreatic diseases, such as chronic pancreatitis (CP), even when endoscopic ultrasound-guided fineneedle aspiration (EUS-FNA) is performed [3, 4].

It is important to find effective biomarkers to make the diagnosis and predict the prognosis precisely so that we can make optimal decisions for chemotherapy or other adjuvant therapies. However, just carbohydrate antigen 19-9 (CA 19-9) and carcinoembryonic antigen (CEA) have been proved having limited diagnostic and prognostic value for PDAC [5]. New effective biomarkers are needed.

AHNAK nucleoprotein 2 (AHNAK2) gene locating at $14 \mathrm{q} 32$ was identified in 2004. AHNAK2 is a large protein $(>600 \mathrm{kDa})$ with a PDZ domain, and it has recently been reported as a potential biomarker of PDAC; however, the previous study did not include tissue-based evidence $[6,7]$. In this present study, we first used tissue microarray (TMA) to determine the expression of AHNAK2 in PDAC. Furthermore, we evaluated the prognostic values of AHNAK2 and made a nomogram model to predict the 1- and 3-year overall survival (OS) rates. 


\section{RESULTS}

\section{Clinical characteristics of patients}

A total of 79 PDAC patients were included in this study, of which 64 had adjacent normal tissues. Surgery was performed between September 2004 and December 2008 and the patients were followed until October 2012 or death. The median followed time (interval between surgery and the last visit or death) was 12 months (range, 0.6-87 months). Fifty-six patients died due to PDAC during the follow-up period. None of the patients received chemotherapy or radiotherapy before or after surgery. The margin was at least $5 \mathrm{~mm}$ far from the tumor. The surgeries were all R0 resections. Age, gender, pathologic grade, TNM stage (according to AJCC), family history, smoking history, alcohol consumption history, and type II diabetes history was provided by the documents. Age and gender information only was available for the $45 \mathrm{CP}$ patients.

The patients with PDAC and the adjacent normal tissue (control) cohort did not show any significant difference in baseline characteristics. The $\mathrm{CP}$ patients were not compared with the other two groups because of limited detailed information (Table 1).

\section{AHNAK2 expression and the correlation with the clinicopathologic features}

Immunohistochemistry was performed to determine the expression of AHNAK2 in tissue samples. As shown in Figure 1A-1L and Table 2, AHNAK2 was mainly located in the cytoplasm and membranes in epithelial cancer cells and significantly overexpressed in the PDAC group compared with the control group $(P<0.0001)$.

A comparison between AHNAK2 expression and the clinicopathologic features showed that AHNAK2 expression did not correlate with any clinicopathologic features (Table 3).

\section{Prognostic values of AHNAK2 expression}

To estimate the clinical prognostic significance of AHNAK2 expression, Kaplan-Meier survival analysis and a log-rank test were performed. As shown in Figure 2A$2 \mathrm{C}$, patients with higher expression of AHNAK2, lymph node metastasis, or a higher AJCC stage had a lower OS.

We also determined whether AHNAK2 expression has more prognostic value in advanced cancers or not. As shown in Figure 2D and 2E, in the sub-group of patients with AJCC grade greater than II or lymph node metastasis, a lower OS was significantly associated with higher AHNAK2 expression.

Furthermore, univariate and Cox multivariate regression analyses were used to confirm that AHNAK2 expression and pathologic grade were confirmed to be independent prognostic factors (Table 4).

\section{Nomogram}

For prediction of the 1- and 3-year OS rates in PDAC patients, AHNAK2 expression and pathologic grade were involved in the nomogram model. The 1and 3-year survival rates are shown in Figure 3A. The c-index of this model was 0.61 . The difference between the observed outcome frequencies and the predicted probabilities are shown in the calibration graph (Figure $3 \mathrm{~B}$ and $3 \mathrm{C}$ ).

\section{DISCUSSION}

The AHNAK protein family has 2 members (AHNAK1 and AHNAK2). AHNAK1 was firstly identified in 1992 [8], which has a variety of functions, including membrane repair $[9,10]$, formation of the bloodbrain barrier [11], and regulation of calcium channels [12].

In recent years, a number of researchers have reported that AHNAK1 is differentially expressed and has a variety of functions in different types of cancer, including pancreatic cancer [13], gastric cancer [14], lung cancer [15, 16], breast cancer [17-23], melanoma $[24,25]$, oral and laryngeal carcinoma [26-28], clear cell renal cell carcinoma [29-31], meningioma [32], and acute lymphocytic leukemia [33].

In those studies, some researchers have demonstrated that AHNAK1 plays an anti-cancer role through epithelial-to-mesenchymal transition (EMT), reorganization of the actin cytoskeleton network, formation of pseudopodial protrusions, or activation of some signaling pathways. In contrast, some other studies have suggested that AHNAK1 is a tumor suppressor by regulating the TGF $/$ Smad signaling pathway [34].

Studies which have focused on the function of AHNAK2 are limited. AHNAK2 is a large protein (> $600 \mathrm{kDa}$ ), which was first detected in 2004. AHNAK2 was shown to have a similar function to AHNAK1. Moreover, these two AHNAKs may be complementary proteins since knocking down AHNAK1 could lead to the overexpression of AHNAK2 and the mouse has no obvious phenotypes [6].

In a recent study, AHNAK2 was confirmed to be an important element of the FGF1 non-classical export pathway that depletes AHNAK2 leads to a decrease in stress-induced FGF1 export [35]. FGF1 has been identified a key driver of many kinds of solid tumors [36]. AHNAK2 has also been reported to be involved in human esophageal squamous carcinoma (ESCC) by regulating protein lysine mono-methyltransferase SMYD2, which is overexpressed or amplified in various types of cancers [37]. 
Table 1: Base line characteristics of patients and tumors

\begin{tabular}{|c|c|c|c|c|}
\hline \multirow[t]{2}{*}{ Characteristics } & \multicolumn{3}{|c|}{ Groups } & \multirow[t]{2}{*}{$P$ value } \\
\hline & $\begin{array}{l}\text { PDAC } \\
(n=79)\end{array}$ & $\begin{array}{c}\text { Control tissue } \\
(n=64)\end{array}$ & $\begin{array}{c}\mathrm{CP} \\
(\mathrm{n}=45)\end{array}$ & \\
\hline Age & $60.8 \pm 11.2$ & $60.2 \pm 10.6$ & $56.4 \pm 8.3$ & 0.75 \\
\hline Gender (Male/female) & $47 / 32$ & $39 / 25$ & $27 / 18$ & 0.86 \\
\hline Family history & 0 & 0 & NG & $>0.99$ \\
\hline Smoking history & $18(22.8 \%)$ & $18(28.1 \%)$ & NG & 0.56 \\
\hline Drinking history & $17(21.5 \%)$ & $18(28.1 \%)$ & NG & 0.44 \\
\hline Type II diabetes & $13(16.5)$ & $12(18.8 \%)$ & NG & 0.52 \\
\hline \multicolumn{5}{|l|}{ Pathology grade } \\
\hline I-II & $57(72.2 \%)$ & & & \\
\hline above II & $22(27.8 \%)$ & & & \\
\hline \multicolumn{5}{|l|}{ Vessel/nerve invasion } \\
\hline Yes & $36(45.6 \%)$ & & & \\
\hline No & $43(54.4 \%)$ & & & \\
\hline \multicolumn{5}{|l|}{ Tumor invasion depth } \\
\hline $\mathrm{T} 1, \mathrm{~T} 2$ & $63(83.5 \%)$ & & & \\
\hline $\mathrm{T} 3, \mathrm{~T} 4$ & $16(16.5 \%)$ & & & \\
\hline \multicolumn{5}{|l|}{$\begin{array}{l}\text { Lymph node } \\
\text { metastasis }\end{array}$} \\
\hline NO & $47(59.5 \%)$ & & & \\
\hline N1 & $32(40.5 \%)$ & & & \\
\hline \multicolumn{5}{|l|}{ Distant metastasis } \\
\hline M0 & $78(98.7 \%)$ & & & \\
\hline M1 & $1(1.3 \%)$ & & & \\
\hline \multicolumn{5}{|l|}{ AJCC-stage } \\
\hline I-II & $36(45.6 \%)$ & & & \\
\hline above II & $43(54.4 \%)$ & & & \\
\hline
\end{tabular}

Data analysis was only performed between PDAC and control groups.

$P<0.05$ was considered as statistically significant.

Only the PDCA cohort had the baseline information of pathology grade, vessel/nerve invasion, TNM stage and AJCC stage.

However, AHNAK2 was never been confirmed as a cancer biomarker until Manoj reported that AHNAK2, together with other 4 proteins, could help diagnose PDAC with high sensitivity and specificity; however, there was no tissue-based evidence in that study [7].

Our study first reported that AHNAK2 is highly expressed in PDAC compared to normal tissues by immunohistochemistry. Interestingly, AHNAK2 was highly expressed in all sub-groups of the PDAC cohort. Thus, we suggest that AHNAK2 is a very important molecule in every stage of PDAC.
We also determined the expression of AHNAK2 in $\mathrm{CP}$ tissues because it is sometimes difficult to distinguish PDAC from CP [38], even though imaging and endoscopic techniques, such as CT, MRI, and EUS-FNA, have been well-established. The results of immunohistochemistry in CP tissues showed decreased expression of AHNAK2, indicating that AHNAK2 could be used in the differential diagnosis when a CP patient has suspected cancer. Unfortunately, we did not have sufficient data to compare the $\mathrm{CP}$ group with the PDAC and control groups. A new cohort with adequate information is needed. 
More importantly, we found that AHNAK2 and pathology grade are independent prognostic factors for PDAC after Kaplan-Meier and Cox regression analyses. Furthermore, AHNAK2 had significant predictive ability in sub-groups of patients with AJCC grade greater than II or lymph node metastasis. These findings suggested that AHNAK2 may have a greater role in advanced cancers. In addition, we created a nomogram and calibration graph to predict the 1- and 3-year survival rates. The c-index was 0.61 . The nomogram might be useful for predicting patients' survival time and give them adjuvant therapies.

Our study had some limitations. First, in this retrospective study the patients may have had some selection bias due to the small number of patients, and the documents did not have the disease-free survival, progression-free survival, and time-to-progress. Second, we did not measure the expression of AHNAK2 in serum samples because it was not possible to obtain blood samples. Third, the CP cohort had insufficient clinical baseline information to compare with the PDAC and CP cohorts. Finally, the expression of AHNAK2 and function in PDAC cell lines and related signaling pathways were not investigated.

In conclusion, we showed that AHNAK2 is highly expressed in PDAC and is an independent prognostic factor. Furthermore, we created a nomogram to predict the 1- and 3-year OS. The most important work in the future will be to perform prospective multicenter clinical trials with external validation cohorts with a focus on elaborate cellular and molecular studies.
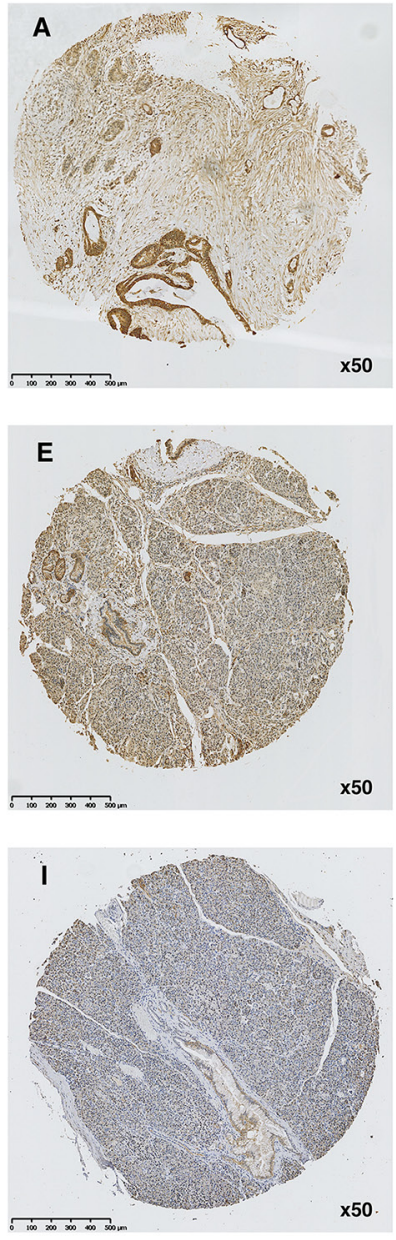
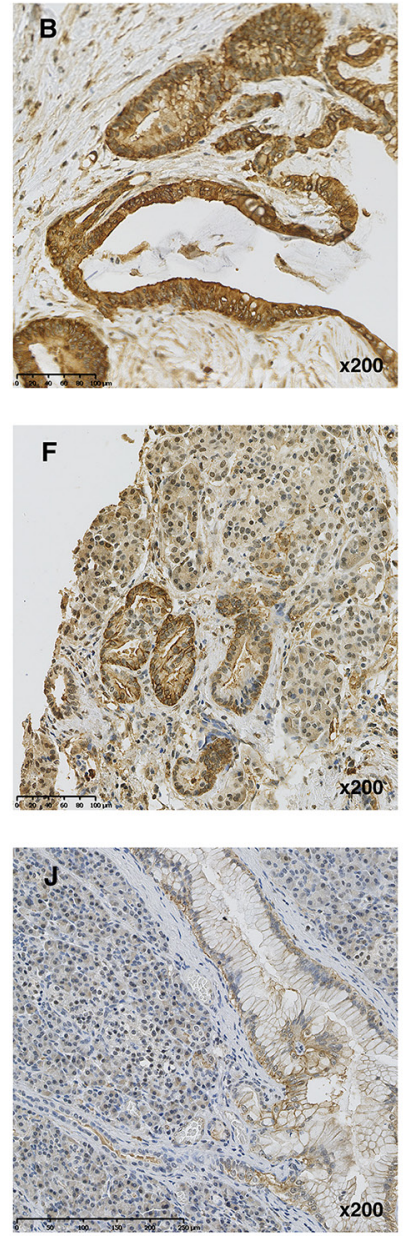
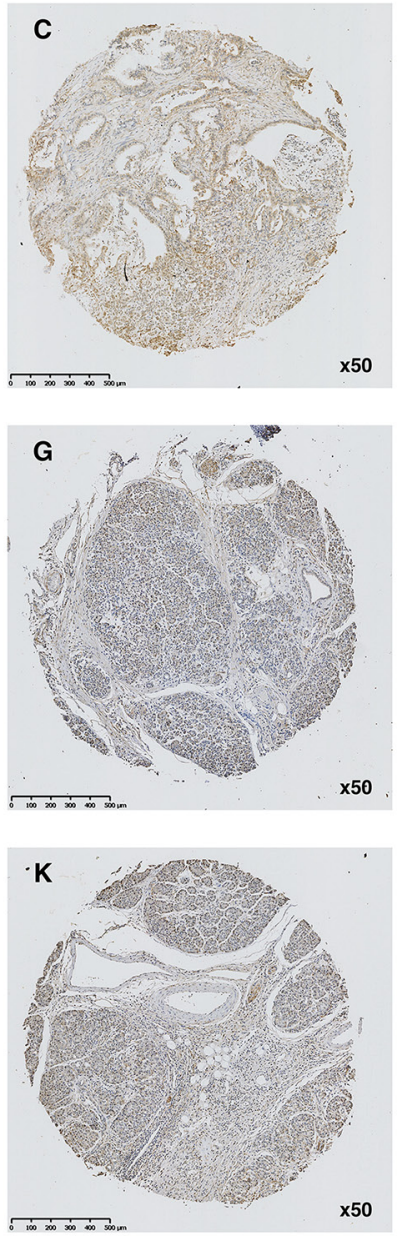
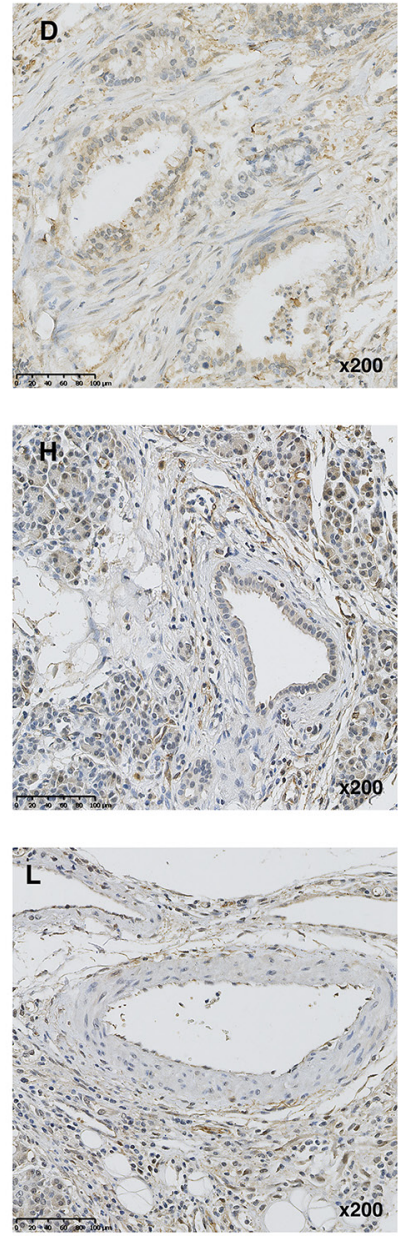

Figure 1: Expression of AHNAK2 in tissue samples. (A-B) High expression of AHNAK2 in PDAC tissue. (C-D) Low expression of AHNAK2 in PDAC tissue. (E-F) High expression of AHNAK2 in adjacent normal tissues. (G-H) Low expression of AHNAK2 in adjacent normal tissues. (I-J) High expression of AHNAK2 in CP tissue. (K-L) Low expression of AHNAK2 in CP tissue. 
Table 2: AHNAK2 expression in PDAC and control cohorts

\begin{tabular}{lccc}
\hline Groups & \multicolumn{2}{c}{ AHNAK2 expression } & P value \\
\cline { 2 - 4 } & High & Low & $<0.0001$ \\
\hline PDAC & $48(60.8 \%)$ & 31 & \\
Control & $1(1.6 \%)$ & 63 & \\
CP & $1(2.2 \%)$ & 44 & \\
\hline
\end{tabular}

$P<0.05$ was considered as statistically significant.

Data analysis was only performed between PDAC and control groups.

Table 3: Association between AHNAK2 expression and the clinicpathological features of PDAC

\begin{tabular}{|c|c|c|c|c|}
\hline \multirow[t]{2}{*}{ Characteristics } & \multirow[t]{2}{*}{ Number } & \multicolumn{2}{|c|}{ AHNAK2 expression } & \multirow[t]{2}{*}{$P$ value } \\
\hline & & High $(n=48)$ & Low $(n=31)$ & \\
\hline \multicolumn{5}{|l|}{ Age (years) } \\
\hline$<65$ & 49 & 31 & 18 & 0.56 \\
\hline$\geq 65$ & 30 & 17 & 13 & \\
\hline \multicolumn{5}{|l|}{ Gender } \\
\hline Male & 47 & 25 & 22 & 0.10 \\
\hline Female & 32 & 23 & 9 & \\
\hline \multicolumn{5}{|l|}{ Pathology grade } \\
\hline I-II & 57 & 35 & 22 & 0.85 \\
\hline above II & 22 & 13 & 9 & \\
\hline \multicolumn{5}{|c|}{ Vessel/nerve invasion } \\
\hline Yes & 36 & 21 & 15 & 0.69 \\
\hline No & 43 & 27 & 16 & \\
\hline \multicolumn{5}{|c|}{ Tumor invasion depth } \\
\hline $\mathrm{T} 1, \mathrm{~T} 2$ & 63 & 41 & 22 & 0.12 \\
\hline $\mathrm{T} 3, \mathrm{~T} 4$ & 16 & 7 & 9 & \\
\hline \multicolumn{5}{|l|}{$\begin{array}{l}\text { Lymph node } \\
\text { metastasis }\end{array}$} \\
\hline N0 & 47 & 26 & 21 & 0.56 \\
\hline $\mathrm{N} 1$ & 32 & 22 & 10 & \\
\hline \multicolumn{5}{|l|}{ Distant metastasis } \\
\hline M0 & 78 & 47 & 31 & $>0.99$ \\
\hline M1 & 1 & 1 & 0 & \\
\hline \multicolumn{5}{|l|}{ AJCC-stage } \\
\hline I-II & 36 & 21 & 15 & 0.69 \\
\hline above II & 43 & 27 & 16 & \\
\hline
\end{tabular}

(Continued) 


\begin{tabular}{|c|c|c|c|c|}
\hline \multirow[t]{2}{*}{ Characteristics } & \multirow[t]{2}{*}{ Number } & \multicolumn{2}{|c|}{ AHNAK2 expression } & \multirow[t]{2}{*}{$P$ value } \\
\hline & & High $(n=48)$ & Low $(n=31)$ & \\
\hline \multicolumn{5}{|l|}{ Family history } \\
\hline Yes & 0 & 0 & 0 & $>0.99$ \\
\hline No & 79 & 48 & 31 & \\
\hline \multicolumn{5}{|l|}{ Smoking history } \\
\hline Yes & 18 & 10 & 8 & 0.61 \\
\hline No & 61 & 38 & 23 & \\
\hline \multicolumn{5}{|l|}{ Drinking history } \\
\hline Yes & 18 & 11 & 7 & 0.97 \\
\hline No & 61 & 37 & 24 & \\
\hline \multicolumn{5}{|l|}{ Type II diabetes } \\
\hline Yes & 13 & 8 & 5 & 0.95 \\
\hline No & 66 & 40 & 26 & \\
\hline
\end{tabular}

$P<0.05$ was considered as statistically significant.
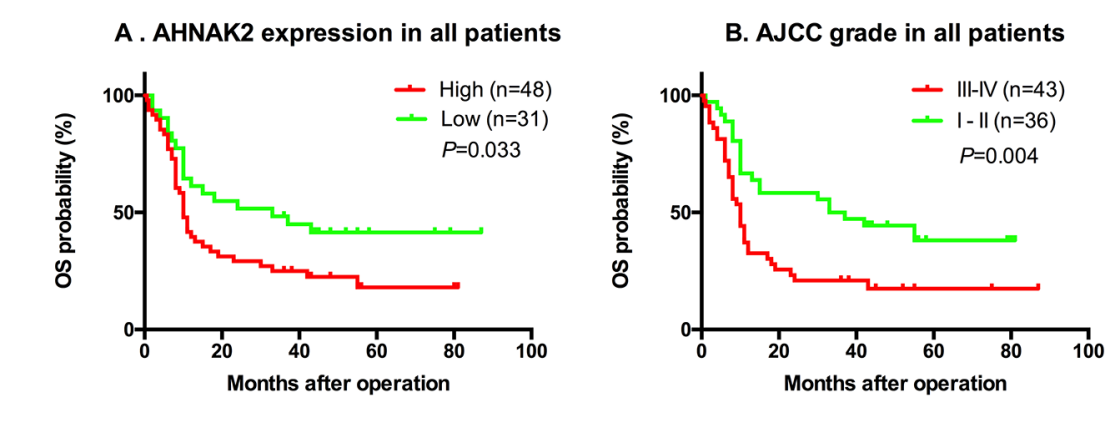

C. Lymph node metastasis in all patients

D. AJCC grade above II
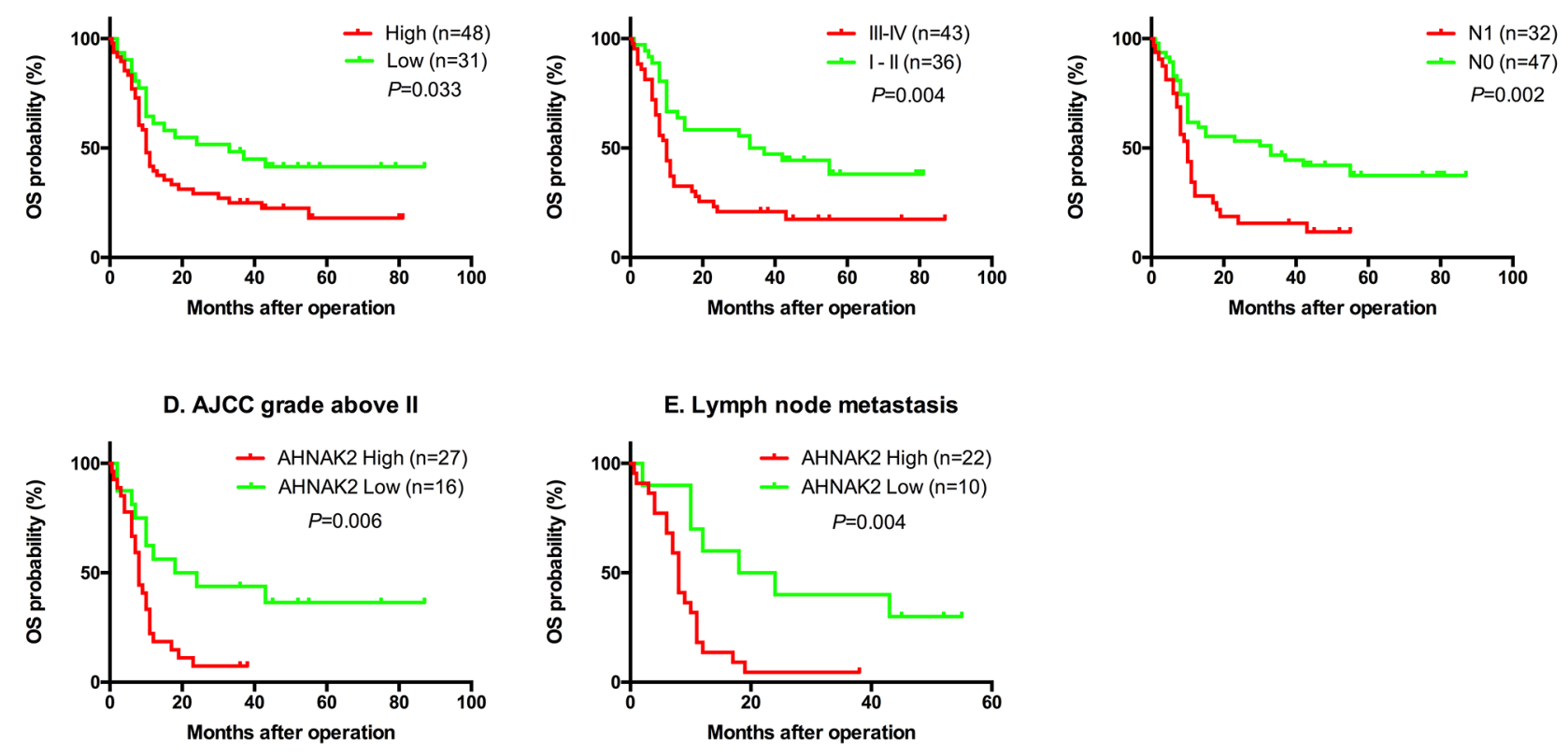

Figure 2: The Kaplan-Meier method analysis with log-rank test for OS. (A-C) Patients with higher expression of AHNAK2, lymph node metastasis or higher AJCC stage had lower OS. (D-E) In the sub-group of AJCC grade above II or lymph node metastasis, the lower OS was significant associated with higher AHNAK2 expression. 
Table 4: Univariate and multivariate analyses of factors associated with survival

\begin{tabular}{lccc}
\hline Factors & Univariate P value & \multicolumn{2}{c}{ Cox regression } \\
\cline { 3 - 4 } & & HR (95\% CI) & P value \\
\hline AHNAK2 expression & $\mathbf{0 . 0 3 3}$ & $\mathbf{2 . 6 2 7}(\mathbf{1 . 3 8 6 - 4 . 9 7 8 )}$ & $\mathbf{0 . 0 0 3}$ \\
Gender & 0.92 & $0.555(0.282-1.086)$ & 0.086 \\
Age & 0.96 & $1.203(0.664-2.177)$ & 0.542 \\
Pathology grade & 0.13 & $\mathbf{3 . 8 7 6}(\mathbf{1 . 8 4 0 - 8 . 1 6 4 )}$ & $<\mathbf{0 . 0 0 1}$ \\
Vessel/nerve invasion & 0.47 & $0.603(0.327-1.113)$ & 0.106 \\
T & 0.96 & $0.959(0.312-2.945)$ & 0.941 \\
N & $\mathbf{0 . 0 0 2}$ & $4.123(0.892-19.051)$ & 0.070 \\
AJCC grade & $\mathbf{0 . 0 0 4}$ & $1.342(0.290-6.220)$ & 0.707 \\
Smoking history & 0.43 & $2.428(0.896-6.578)$ & 0.081 \\
Drinking history & 0.92 & $0.753(0.271-2.093)$ & 0.587 \\
Type II diabetes & 0.65 & $0.711(0.336-1.504)$ & 0.372 \\
\hline
\end{tabular}

$P<0.05$ was considered as statistically significant.

Distant metastasis and family history data was not shown in the table because of the too small number of patients in the sub-groups.

A

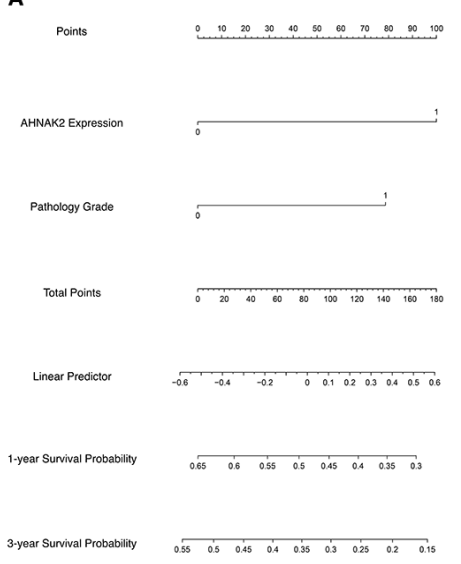

B

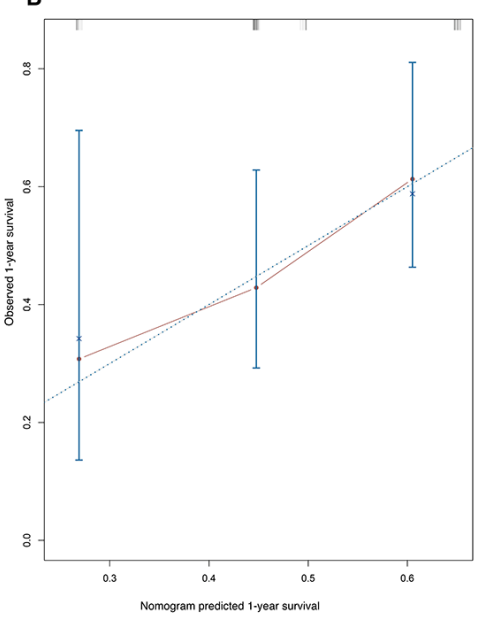

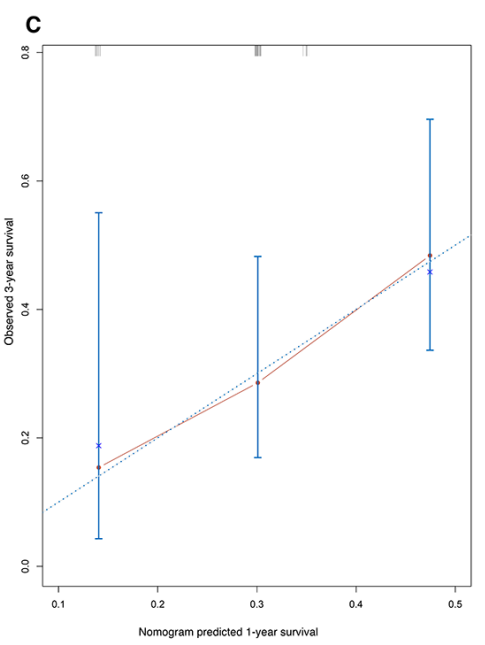

Figure 3: The nomogram and calibration graph. (A) The nomogram model based on the Cox regression to predict 1-year and 3 -year survival rate. The c-index of this model was 0.61 . (B-C) The calibration graph to show difference between the observed outcome frequencies and the predicted probabilities. 


\section{MATERIALS AND METHODS}

\section{Patients and tissue microarray (TMA)}

The PDAC TMA (diameter, $1.5 \mathrm{~mm} ; 4 \mu \mathrm{m}$ ) constructed by Biochip (Shanghai, China) included 80 primary PDAC samples with adjacent normal tissues and 20 single primary PDAC tissues. After excluding squamous carcinoma, mucous carcinoma, and damaged tissues, 79 PDAC and 64 adjacent normal tissues were available. The pancreatitis TMA (diameter, $1.5 \mathrm{~mm} ; 4 \mu \mathrm{m}$ ) was obtained from US Biomax (Rockville, MD, USA) and included 3 acute pancreatitis (excluded) and 45 chronic pancreatitis samples.

Ethics Committee approval was obtained by Shanghai Biochip and Xi'an Alena-bio Companies that provided the TMAs.

\section{Immunohistochemistry}

The TMAs were deparaffinized, rehydrated, and washed with PBS, followed by antigen retrieval using EDTA ( $\mathrm{pH}$ 9.0) for 5 min under high pressure. The slides were then incubated with $3 \% \mathrm{H}_{2} \mathrm{O}_{2}$ for 15 min to block endogenous peroxidase. Then, the slides were incubated with rabbit anti-human AHNAK2 polyclonal primary antibody (HPA004145; Sigma-Aldrich, St. Louis, MO, USA) at a 1:500 dilution overnight at $4{ }^{\circ} \mathrm{C}$. After PBS washing, the secondary antibody and DAB (PV8000; ZSGB-BIO, Beijing, China) were added as a chromogen. Finally, the slides were counterstained with hematoxylin. The negative control was performed using pre-immune rabbit serum at the same dilution.

The TMAs were independently scanned by two professional pathologists at $\times 200$ magnification. ImageJ (version 1.50i; National Institutes of Health, Bethesda, MD, USA) was used to measure the percentage of positively-stained epithelial cancer cells, and the percentage was scored as 0 (none), $1(<10 \%), 2(10-50 \%)$, $3(51-80 \%)$, and $4(>80 \%)$. The intensity of staining was scored as follows: 0 (no staining); 1 (weak); 2 (moderate); and 3 (strong). The total score was multiplied by the intensity and the percentage score; $0-6$ was low expression and 7-12 was high expression $[39,40]$.

\section{Statistical analyses}

Data analyses were performed using Graphpad Prism 6 Software (La Jolla, CA, USA) and R 3.3.1 software (http://www.R-project.org). The base line and AHNAK2 expression data were evaluated using a t-test and Fishers exact text. OS was calculated using the Kaplan-Meier method with a log-rank test. The Cox proportional hazards regression model was performed for multivariate analyses. The nomogram was based on the Cox model. Furthermore, we developed a calibration curve to compare the relationship between the observed outcomes and the predicted probabilities. $P<0.05$ was considered statistically significant.

\section{Abbreviations}

AHNAK2: AHNAK Nucleoprotein 2; PDAC: Pancreatic Ductal Carcinoma; CP: Chronic Pancreatitis; CA 19-9: Carbohydrate Antigen 19-9; CEA: Carcinoembryonic Antigen; OS: Overall Survival; DFS: Disease Free Survival; PFS: Progression Free Survival; TTP: Time to Progress; IHC: Immunohistochemistry; TMA: Tissue Microarray; AJCC: American Joint Committee on Cancer; DAB: Diaminobenzidine; PBS: Phosphate Buffered Saline; EDTA: Ethylene Diamine Tetraacetic Acid

\section{Author contributions}

Jianyu Hao responsible for this article conceived and designed the study. Di Lu, andJunxiong Wang performed the experiments, Xiaoyan Shi and Bing Yue gave the pathology diagnosis of IHC. Di Lu completed the data analysis. $\mathrm{Di} \mathrm{Lu}$ wrote the paper and sent the manuscript. All authors read and approved the manuscript.

\section{ACKNOWLEDGMENTS}

This study was supported by Medical Research Center, Beijing Chao-Yang Hospital, Capital Medical University.

\section{CONFLICTS OF INTEREST}

There were no conflicts of interest of any author in this study.

\section{FUNDING}

This study was funded by National Natural Science Foundation of China (81172319 and 81470888) and Specialized Research Fund for the Doctoral Program of Higher Education of China (20131107110020).

\section{REFERENCES}

1. Ferlay J, Soerjomataram I, Dikshit R, Eser S, Mathers C, Rebelo M, Parkin DM, Forman D, Bray F. Cancer incidence and mortality worldwide: sources, methods and major patterns in GLOBOCAN 2012. Int J Cancer. 2015; 136: E359-86. doi: 10.1002/ijc.29210.

2. Siegel RL, Miller KD, Jemal A. Cancer statistics, 2016. CA Cancer J Clin. 2016; 66: 7-30. doi: 10.3322/caac.21332.

3. Touchefeu Y, Le Rhun M, Coron E, Alamdari A, Heymann MF, Mosnier JF, Matysiak T, Galmiche JP. Endoscopic 
ultrasound-guided fine-needle aspiration for the diagnosis of solid pancreatic masses: the impact on patient-management strategy. Aliment Pharmacol Ther. 2009; 30: 1070-7. doi: 10.1111/j.1365-2036.2009.04138.x.

4. Yadav D, Lowenfels AB. The Epidemiology of Pancreatitis and Pancreatic Cancer. Gastroenterology. 2013; 144: 1252 61. doi: 10.1053/j.gastro.2013.01.068.

5. Gattani AM, Mandeli J, Bruckner HW. Tumor markers in patients with pancreatic carcinoma. Cancer. 1996; 78: 57-62.] [Winter JM, Yeo CJ, Brody JR. Diagnostic, prognostic, and predictive biomarkers in pancreatic cancer. J Surg Oncol. 2013; 107: 15-22.

6. Komuro A, Masuda Y, Kobayashi K, Babbitt R, Gunel M, Flavell RA, Marchesi VT. The AHNAKs are a class of giant propeller-like proteins that associate with calcium channel proteins of cardiomyocytes and other cells. Proc Natl Acad Sci U S A. 2004; 101:4053-8.

7. Bhasin MK, Ndebele K, Bucur O, Yee EU, Otu HH, Plati J, Bullock A, Gu X, Castan E, Zhang P, Najarian R, Muraru MS, Miksad R, et al. Meta-analysis of transcriptome data identifies a novel 5-gene pancreatic adenocarcinoma classifier. Oncotarget. 2016; 7: 23263-81. doi: 10.18632/oncotarget.8139.

8. Shtivelman E, Cohen FE, Bishop JM. A human gene (AHNAK) encoding an unusually large protein with a 1.2-microns polyionic rod structure. Proc Natl Acad Sci U S A. 1992; 89: 5472-6.

9. Huang Y, Laval SH, van Remoortere A, Baudier J, Benaud C, Anderson LV, Straub V, Deelder A, Frants RR, den Dunnen JT, Bushby K, van der Maarel SM. AHNAK, a novel component of the dysferlin protein complex, redistributes to the cytoplasm with dysferlin during skeletal muscle regeneration. FASEB J. 2007; 21: 732-42.

10. Benaud C, Gentil BJ, Assard N, Court M, Garin J, Delphin C, Baudier J. AHNAK interaction with the annexin 2/S100A10 complex regulates cell membrane cytoarchitecture. J Cell Biol. 2004; 164: 133-44.

11. Gentil BJ, Benaud C, Delphin C, Remy C, Berezowski V, Cecchelli R, Feraud O, Vittet D, Baudier J. Specific AHNAK expression in brain endothelial cells with barrier properties. J Cell Physiol. 2005; 203: 362-71.

12. Haase H, Alvarez J, Petzhold D, Doller A, Behlke J, Erdmann J, Hetzer R, Regitz-Zagrosek V, Vassort G, Morano I. Ahnak is critical for cardiac $\mathrm{Ca}(\mathrm{V}) 1.2$ calcium channel function and its beta-adrenergic regulation. FASEB J. 2005; 19: 1969-77.

13. Goonesekere NC, Wang X, Ludwig L, Guda C. A meta analysis of pancreatic microarray datasets yields new targets as cancer genes and biomarkers. PLoS One. 2014; 9: e93046. doi: 10.1371/journal.pone.0093046.

14. Chen YR, Juan HF, Huang HC, Huang HH, Lee YJ, Liao MY, Tseng CW, Lin LL, Chen JY, Wang MJ, Chen JH, Chen YJ. Quantitative proteomic and genomic profiling reveals metastasis-related protein expression patterns in gastric cancer cells. J Proteome Res. 2006; 5: 2727-42.
15. Keshamouni VG, Michailidis G, Grasso CS, Anthwal S, Strahler JR, Walker A, Arenberg DA, Reddy RC, Akulapalli S, Thannickal VJ, Standiford TJ, Andrews PC, Omenn GS. Differential protein expression profiling by iTRAQ2DLC-MS/MS of lung cancer cells undergoing epithelialmesenchymal transition reveals a migratory/invasive phenotype. J Proteome Res. 2006; 5: 1143-54.

16. Chou CH, Cheng YF, Siow TY, Kumar A, Peck K, Chang C. SCUBE3 regulation of early lung cancer angiogenesis and metastatic progression. Clin Exp Metastasis. 2013; 30: 741-52. doi: 10.1007/s10585-013-9575-8.

17. Pal M, Moffa A, Sreekumar A, Ethier SP, Barder TJ, Chinnaiyan A, Lubman DM. Differential phosphoprotein mapping in cancer cells using protein microarrays produced from 2-D liquid fractionation. Anal Chem. 2006; 78: 702-10.

18. Silva TA, Smuczek B, Valadão IC, Dzik LM, Iglesia RP, Cruz MC, Zelanis A, de Siqueira AS, Serrano SM, Goldberg GS, Jaeger RG, Freitas VM. AHNAK enables mammary carcinoma cells to produce extracellular vesicles that increase neighboring fibroblast cell motility. Oncotarget. 2016; 7: 49998-50016. doi: 10.18632/oncotarget.10307.

19. Johansson HJ, Sanchez BC, Forshed J, Stål O, Fohlin H, Lewensohn R, Hall P, Bergh J, Lehtiö J, Linderholm BK. Proteomics profiling identify CAPS as a potential predictive marker of tamoxifen resistance in estrogen receptor positive breast cancer. Clin Proteomics. 2015; 12: 8. doi: 10.1186/ s12014-015-9080-y.

20. Caruso JA, Stemmer PM. Proteomic profiling of lipid rafts in a human breast cancer model of tumorigenic progression. Clin Exp Metastasis. 2011; 28: 529-40. doi: 10.1007/ s10585-011-9389-5.

21. Parisis N, Metodieva G, Metodiev MV. Pseudopodial and $\beta$-arrestin-interacting proteomes from migrating breast cancer cells upon PAR2 activation. J Proteomics. 2013; 80: 91-106. doi: 10.1016/j.jprot.2012.12.024.

22. Chen H, Pimienta G, Gu Y, Sun X, Hu J, Kim MS, Chaerkady R, Gucek M, Cole RN, Sukumar S, Pandey A. Proteomic characterization of Her2/neu-overexpressing breast cancer cells. Proteomics. 2010; 10: 3800-10. doi: 10.1002/pmic.201000297.

23. M.H. Kabir, E.J. Suh, C. Lee. Comparative phosphoproteome analysis reveals more ERK activation in MDA-MB-231 than in ECF-7. Int. J. Mass Spectrom. 2012; 309: 1-12.

24. Baruthio F, Quadroni M, Rüegg C, Mariotti A. Proteomic analysis of membrane rafts of melanoma cells identifies protein patterns characteristic of the tumor progression stage. Proteomics. 2008; 8: 4733-47. doi: 10.1002/ pmic. 200800169.

25. Lugassy C, Lazar V, Dessen $\mathrm{P}$, van den Oord JJ, Winnepenninckx V, Spatz A, Bagot M, Bensussan A, Janin A, Eggermont AM, Barnhill RL. Gene expression profiling of human angiotropic primary melanoma: selection of 15 differentially expressed genes potentially involved in 
extravascular migratory metastasis. Eur J Cancer. 201; 47: 1267-75. doi: 10.1016/j.ejca.2011.01.009.

26. Dumitru CA, Bankfalvi A, Gu X, Zeidler R, Brandau S, Lang S. AHNAK and inflammatory markers predict poor survival in laryngeal carcinoma. PLoS One. 2013; 8: e56420. doi: 10.1371/journal.pone.0056420.

27. Cui X, Zhu W, Wang P, Wang X. Tetrandrine Inhibits the Intracellular Calcium Ion Level and Upregulates the Expression of Brg1 and AHNAK in Hep-2 Cells. Clin Lab. 2015; 61: 1569-76.

28. Winck FV, Belloni M, Pauletti BA, Zanella Jde L, Domingues RR, Sherman NE, Paes Leme AF. Phosphoproteome analysis reveals differences in phosphosite profiles between tumorigenic and non-tumorigenic epithelial cells. J Proteomics. 2014; 96: 67-81. doi: 10.1016/j.jprot.2013.10.039.

29. White NM, Masui O, Desouza LV, Krakovska O, Metias S, Romaschin AD, Honey RJ, Stewart R, Pace K, Lee J, Jewett MA, Bjarnason GA, Siu KW, Yousef GM. Quantitative proteomic analysis reveals potential diagnostic markers and pathways involved in pathogenesis of renal cell carcinoma. Oncotarget. 2014; 5: 506-18. doi: 10.18632/oncotarget.1529

30. Xu X, Hou Y, Yin X, Bao L, Tang A, Song L, Li F, Tsang $\mathrm{S}, \mathrm{Wu} \mathrm{K}, \mathrm{Wu} \mathrm{H}, \mathrm{He} \mathrm{W}$, Zeng L, Xing M, et al. Singlecell exome sequencing reveals single-nucleotide mutation characteristics of a kidney tumor. Cell. 2012; 148: 886-95. doi: 10.1016/j.cell.2012.02.025.

31. Guo G, Gui Y, Gao S, Tang A, Hu X, Huang Y, Jia W, Li Z, He M, Sun L, Song P, Sun X, Zhao X, et al. Frequent mutations of genes encoding ubiquitin-mediated proteolysis pathway components in clear cell renal cell carcinoma. Nat Genet. 2011; 44: 17-9. doi: 10.1038/ng.1014.

32. Sharma S, Ray S, Mukherjee S, Moiyadi A, Sridhar E, Srivastava S. Multipronged quantitative proteomic analyses indicate modulation of various signal transduction pathways in human meningiomas. Proteomics. 2015; 15: 394-407. doi: 10.1002/pmic.201400328.
33. Chiaretti S, Li X, Gentleman R, Vitale A, Vignetti M, Mandelli F, Ritz J, Foa R. Gene expression profile of adult T-cell acute lymphocytic leukemia identifies distinct subsets of patients with different response to therapy and survival. Blood. 2004; 103: 2771-8.

34. Lee IH, Sohn M, Lim HJ, Yoon S, Oh H, Shin S, Shin JH, Oh SH, Kim J, Lee DK, Noh DY, Bae DS, Seong JK, Bae YS. Ahnak functions as a tumor suppressor via modulation of TGF $\beta /$ Smad signaling pathway. Oncogene. 2014; 33:4675-84. doi: 10.1038/onc.2014.69.

35. Kirov A, Kacer D, Conley BA, Vary CP, Prudovsky I. AHNAK2 Participates in the Stress-Induced Nonclassical FGF1 Secretion Pathway. J Cell Biochem. 2015; 116: 152231. doi: $10.1002 /$ jcb.25047.

36. Jeffers M, LaRochelle WJ, Lichenstein HS. Fibroblast growth factors in cancer: therapeutic possibilities. Expert Opin Ther Targets. 2002; 6: 469-82.

37. Olsen JB, Cao XJ, Han B, Chen LH, Horvath A, Richardson TI, Campbell RM, Garcia BA, Nguyen H. Quantitative Profiling of the Activity of Protein Lysine Methyltransferase SMYD2 Using SILAC-Based Proteomics. Mol Cell Proteomics. 2016; 15:892-905. doi: 10.1074/mcp. M115.053280.

38. Varadarajulu S, Tamhane A, Eloubeidi MA. Yield of EUSguided FNA of pancreatic masses in the presence or the absence of chronic pancreatitis. Gastrointest Endosc. 2005; 62: 728-36.

39. Weichert W, Röske A, Gekeler V, Beckers T, Ebert MP, Pross M, Dietel M, Denkert C, Röcken C. Association of patterns of class I histone deacetylase expression with patient prognosis in gastric cancer: a retrospective analysis. Lancet Oncol. 2008; 9: 139-48. doi: 10.1016/ S1470-2045(08)70004-4.

40. Lin C, Zhao GC, Xu YD, Wang DS, Jin DY, Ji Y, Lou WH, $\mathrm{Wu}$ WC. Increased expression of $\alpha$ Tubulin is associated with poor prognosis in patients with pancreatic cancer after surgical resection. Oncotarget. 2016; 7: 60657-64. doi: 10.18632/oncotarget.10630. 